\section{The Corporate Conundrum: How to Blend People and Process to Improve Firm Performance}

\author{
Thanuja Rathakrishnan ${ }^{1}$ \\ Siew Imm $\mathrm{Ng}^{2}$ (D) \\ Jo Ann $\mathrm{Ho}^{3}$ (iD \\ Dahlia Zawawi ${ }^{4}$ (D)
}

\begin{abstract}
Purpose - One of the challenges in the business world is maximising effectiveness and firm performance. This study proposes that the right blend of people (with openness to change and self-transcendence values) and process (effectuation) would result in innovative behaviour and firm performance.

Theoretical framework - The effectuation process has been found to be useful in promoting innovativeness, especially among small firms whose resources are scarce. This relationship is also true in large firms, although these have more resources and operate in a relatively stable environment.
\end{abstract}

Design/methodology/approach - Using a snowball sampling approach, a total of 206 completed questionnaires were collected online from employees involved in decision making and innovative work processes in multinational companies in Selangor, Malaysia. PLS-SEM was used to analyse the data.

Findings - The right people (who are open to change or self-transcendent) blended with the right process (effectuation) were found to positively predict innovative behaviour and firm performance. Effectuation and innovative behaviour also mediated the relationships between individual values and firm performance, suggesting that people and process should coexist to enhance firm performance.

Research Practical \& Social implications - Effectuation is scarcely practised in large firms. Therefore, we suggest that large firms encourage the use of effectuation through training. As the practice is better received among individuals who are open to change and self-transcendent, these values could also be used as hiring criteria.

Originality/value - This study contributes to the literature by analysing the roles of people and process in optimising firm performance, and identifying effectuation and innovative behaviour as mechanisms that link individual values to firm performance.

Keywords - Effectuation Decision Making, Firm Performance, Individual Values, Innovative Behaviour, Multinational Companies (MNCs)

1. Universiti Putra Malaysia, School of Business and Economics, Serdang, Malaysia

How to cite:

Rathakrishnan, T., Ng, S. I., Ho, J. A., \& Zawawi, D. (2021). The Corporate Conundrum: How to Blend People and Process to Improve Firm Performance. Revista Brasileira de Gestão de Negócios, 22(1), firstpage-lastpage.
226

Received on:

09/10/2019

Approved on:

$11 / 10 / 2020$

Responsible Editor:

Prof. Dr. Pattanee Susomrith

\section{Evaluation process:}

Double Blind Review

Reviewers:

Ewelina Purc; Igor Laine.

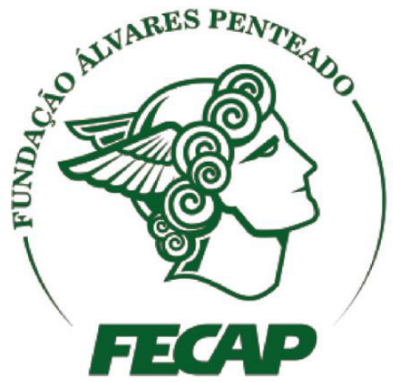

Revista Brasileira de Gestáo de Negócios

https://doi.org/10.7819/rbgn.v23i2.4099 


\section{Introduction}

Today's business environment is undergoing an aggressive transformation and relentless changes in the name of evolution. These dynamic business conditions lead to uncertainty caused by a lack of knowledge about possible future states of affairs (Knight, 1921). Given the complexity and ambiguity of the business world, one of the most challenging conundrums lies in maximising effectiveness and firm performance. This is apparent among multinational companies (MNCs), especially those in the Malaysian manufacturing sector. The manufacturing sector has always focused on processes to increase production (Brettel, Bendig, Keller, Friederichsen, \& Rosenberg 2014). However, the current business conditions have sparked conflicting viewpoints and arguments that priority should be given to either people or processes in the highly uncertain environment.

Previous studies have devoted much attention to what constitutes good firm performance (Crespo, Griffith, \& Lages, 2014; Jasimuddin \& Hasan, 2015; Jones \& Linderman, 2014; Mollick, 2012). However, the following question remains: "What are the roles of people (individual values) and process (effectuation) in advancing firm performance?" This is of concern due to Malaysia's stagnant ranking in the Global Innovation Index (GII). Malaysia's ranking in the GII has dropped from 28 in 2010 to 37 in 2017, with a slight increase (35) in 2018 and 2019 (Malaysia Science and Technology Information Centre, 2019). In spite of the government's efforts and investment in human capital and processes (e.g. R\&D, training, technology, workshops, industry-led programs, education) (Economic Planning Unit, 2015), innovative outcomes seem to be declining. The decreasing trend in innovation since 2010 is alarming as it indicates that Malaysia is losing its focus on innovativeness, which serves as a competitive advantage and a business sustainability tool in firms (Singh, Garg, \& Deshmukh, 2008). If these issues are left unresolved, Malaysia will fall far behind in innovation and, consequently, firm performance. Therefore, this study endeavoured to identify the right blend of people and process to achieve the desired outcomes (innovative behaviour and firm performance) that ensure sustainability in today's global economy.

The extant literature, predominantly in the field of strategic management, claims that the secret of good firm performance lies in a firm's process (Arasa \& K’Obonyo, 2012; Oliveira, Maçada, \& Oliveira, 2016).
This inference is made based on investigations into organisational structure-related factors alone, which depict the organisational process. Conversely, literature in the management and human resources field argues that firm performance is affected by the human capital of firms. For instance, previous studies have found that top managers' support is significantly and positively related to financial performance (Lo, Wang, Wah, \& Ramayah, 2016), that individuals' self-efficacy and effort influence sales performance (Donassolo \& Matos, 2014), and that employees' entrepreneurial competencies are crucial for obtaining higher performance (Gerli, Gubitta, \& Tognazzo, 2011). Both fields have made fruitful attempts to prove their respective points. While human resources journals generally conclude that ignoring people leads to process paralysis, strategic management journals counter that the organisational process eventually determines how individuals perform. As such, whether to focus on people or process remains a puzzling question, especially for MNCs.

Despite the potential importance of both people and process in explaining firm performance, they have seldom been studied within a single framework. Therefore, this study strived to narrow this gap by including both people (individual values) and process (effectuation decision making) factors to understand how they achieve the desired outcomes (innovative behaviour and firm performance). In particular, the study posited that firm performance depends on individuals and their competencies in carrying out the firm's process diligently.

In addition, this study expanded previous viewpoints on the sequence of the influence of people and process on firm performance. The individual aspect focused on individuals with values that support the use of an effectuation process, which subsequently enhances innovative behaviour and firm performance. The values embraced by individuals have been found to explain employee performance in the past, thus increasing the chances of such values influencing firm performance as well. However, the value-performance relationship has shown contradictory results, as the studies have highlighted both positive and negative relationships (Ahmic, Sunje, \& Kurtic, 2016; Purc \& Laguna, 2019; Sousa \& Coelho, 2011). Due to these discrepancies in the literature, this study suggested the introduction of mediators to link individual values and performance. Two mediators were proposed: (1) effectuation, which is a decision-making process; and (2) innovative behaviour, which is an intermediate outcome 
leading to firm performance. The study thus aimed to answer the following research questions:

a) What are the roles of people (individual values) and process (effectuation) in advancing firm performance?

b) Does effectuation mediate the relationship between individual values and innovative behaviour?

c) Does innovative behaviour mediate the relationship between effectuation and firm performance?

According to the GE Global Barometer (2014), most firms in Malaysia have been found to adopt causation and structured decision-making processes. In other words, effectuation is still in its infancy in promoting innovative behaviour in manufacturing MNCs in Malaysia. Hence, this study intended to test if the relationships proposed above are applicable to MNCs.

\section{Literature Review}

\section{I People to process}

The study of Nelson and Winter (1982) on the Toyota Production System found that success is based on routines and organisational processes. This indicates that human capital is ultimately replaceable and interchangeable as long as individuals receive the same extensive training. Mollick (2012) explains that organisations with a consistent and reliable process "do not rely on any individual worker's skills, but rather, firm-level processes to hire and train the appropriate individuals for the appropriate roles." However, the study of Mollick (2012) also found that there are individual differences between middle managers and innovators in terms of firm performance. In simpler terms, individuals uniquely contribute to the performance of a firm.

The study of Yildiz, Murtic, Zander and Richtnér (2019) looked into individual-level capability (i.e. individuals' capability to recognise, assimilate and exploit new knowledge) for the effective management of the knowledge process in MNCs. The results of their study showed that individuals' intrinsic motivation and overall ability are key antecedents to absorptive capacity, whereas extrinsic motivation is not a significant predictor. Michailova and Nielsen (2006) also mentioned that knowledge creation and knowledge sharing between individuals can be developed through the social exchange of information between them (within or among organisations), which enhances the knowledge process in MNCs.

According to Yildiz et al. (2019), studies of the knowledge management process have opened up avenues for research on organisational learning and knowledge management. However, the authors draw attention to the fact that many studies have examined knowledge management from a macro perspective (e.g. knowledge management orientation in firms, organisational communication transfer) (Hutzschenreuter \& Horstkotte, 2010; Wang, Hult, Ketchen, \& Ahmed, 2009), while less consideration has been given to the micro or individual perspective. As such, this study responded to the concern raised by Yildiz et al. (2019) by looking into the role of individual values in the decision-making process in MNCs.

\subsection{Process to performance}

MNCs employ process control mechanisms to coordinate units in order to meet global organisational objectives (Brenner \& Ambos, 2013; Jasimuddin \& Hasan, 2015; Jones \& Linderman, 2014). Process control specifies desirable employee behaviour and includes centralisation and standardisation, as well as written manuals, to ensure that employees adhere to specified processes (Brenner \& Ambos, 2013). Additionally, Jasimuddin and Hasan (2015) identified that integration processes in MNCs (e.g. learning and development, top management support, centralisation) are positively linked to knowledge sharing that promotes the successful performance of MNCs.

In equal measure, previous research recognises the drawbacks of process control, centralisation and standardisation for firm performance. For example, Jones and Linderman (2014) found that process control is not related to competitive efficiency. Further analysis proved that as the level of competition increases, process control discourages innovation performance. This is because innovative outcomes require new ideas pertaining to processes and products, and require organisations to go beyond structured, repetitive processes that minimise variation (Aboelmaged, 2012; Jaussaud \& Schaaper, 2006; Jones \& Linderman, 2014). However, a recent study by Zarzycka, Dobroszek, Lepistö and Moilanen (2019) provided evidence of the coexistent relationship between innovation, standardisation and management 
control. Their study refuted previous studies that found have that process control hinders innovation (Jaussaud \& Schaaper, 2006; Jones \& Linderman, 2014).

Studies have also revealed that the knowledge transfer process improves firm performance (Crespo et al., 2014; Jones \& Linderman, 2014). According to Jones and Linderman (2014), incremental learning via knowledge transfer lies within the scope of process improvement. Their study found that process improvement does not lead directly to innovation; however, innovative outcomes are achieved under intense competition. As such, the importance of knowledge sharing and the knowledge transfer process have led to the introduction of the management information system (MIS) in MNCs to convey skills and knowledge globally (Moilanen 2007; Whitaker, Ekman, \& Thompson, 2017), which subsequently affects firm performance. This is in line with the work of Darroch (2005), who highlighted that subsidiaries without an effective knowledge management orientation could cause underutilisation of information and knowledge, thereby decreasing firms' innovation performance.

While previous studies have delved into managerial (control) and technological (MIS) processes, they fail to consider the decision-making process. Therefore, this study reflected on the effectuation decision-making process, which focuses on flexibility and partnership (idea and resource sharing).

\subsection{The effectuation process in MNCs}

The concept of effectuation was established by Sarasvathy in 2001. Based on interviews with 27 expert entrepreneurs, she found that entrepreneurs are street-smart as opposed to book-smart. In other words, entrepreneurs do not employ the causation approach typically taught in business schools (book-smart). Instead, they make decisions that are within their control (street-smart). Causation refers to a decision-making process that relies on goal setting, prediction, market analysis, profits, and revenue maximisation strategies. Since companies face dynamism and uncertainties, applying causation would be both challenging and irrelevant (Sarasvathy, 2001). The effectuation theory, in this regard, is a set of heuristics that offers an alternative way of thinking, deciding, and acting in uncertain situations. There are four principles under the effectuation approach, i.e. experimentation, affordable loss, pre-commitments, and flexibility.
Experimentation finds alternative ways through the available means at hand (Sarasvathy, 2001). In other words, individuals solve issues or improvise ideas using the different resources available to them. The second principle, affordable loss, refers to the amount of loss that is acceptable. The idea is to risk as much as one is willing to lose (Chandler, DeTienne, \& Mumford, 2007). Successful expert entrepreneurs focus on experimenting with multiple strategies through their available means, while concurrently minimising risks and costs (Brettel, Mauer, Engelen, \& Küppe, 2012).

The third principle, known as pre-commitment, encourages relationship engagement with customers, suppliers, and even prospective competitors to form strategic alliances (Brettel et al., 2012). This principle suggests transparency among stakeholders, which is crucial for knowledge sharing between them (Lepistö, Mäkitalo-Keinonen, \& Valjakka, 2019). The fourth principle is flexibility, which suggests that individuals must embrace both positive and negative events (Evald $\&$ Senderovitz, 2013). Employees are thus expected to make the necessary changes to overcome unexpected events (Sarasvathy, 2001). By doing so, underlying potential opportunities can be exploited as most opportunities derive from unpredicted events.

Prior studies have shown that effectuation is heavily associated with smaller firms (e.g. SMEs, family business, start-ups), as it is a suitable decision-making logic for the business nature of such firms. This is due to the fact that smaller firms face high uncertainties such as resource limitations (financial, human capital, innovation structure, market power) and business competition (Sarasvathy, 2001; 2008), which require them to make quick decisions (Radam, Abu, \& Abdullah, 2008; Sarasvathy, 2001). Smaller firms are also flexible due to their simple systems and procedures. In other words, smaller firms have shorter decision-making chains than large enterprises (Singh et al., 2008). These points have led to more attention being given to the application of effectuation in smaller firms.

While most studies have established that effectuation drives performance in the context of SMEs (Berends, Jelinek, Reymen, \& Stultiëns, 2014; McKelvie, DeTienne, \& Chandler, 2013), family businesses (Barrett \& Moores, 2012), online businesses (Daniel, Domenico, \& Sharma, 2015), and start-up firms (Harms \& Schiele, 2012), the present study questioned if this relationship holds true for manufacturing MNCs in Malaysia. Like 
small firms, MNCs, specifically manufacturing firms, face high uncertainties and struggle with innovation as a result of the fast-changing business environment (Fallah \& Lechler, 2008; Sniazhko, 2019). There is, in fact, evidence that effectuation may work in MNCs. For example, the effectuation approach has been reported to enhance innovation in R\&D departments (Brettel et al., 2012) and in project management (Küpper \& Burkhart, 2009). These are units that are less bound by the rules or procedures of MNCs to be innovative. In addition, there are specific job positions in manufacturing MNCs that deal with innovation, such as engineers or project managers who are given more flexibility and autonomy (Corry \& Cormican, 2019; Thamhain, 2003; Zeschky, Daiber, Widenmayer, \& Gassmann, 2014). This suggests that effectuation may be applicable to manufacturing MNC employees who deal with innovative work.

\subsection{Innovative behaviour}

Innovation adds value to a firm's "product, service, work process, marketing, distribution, and policy" (Ratnaningsih, Prasetyo, \& Prihatsanti, 2016, p. 85). Therefore, innovation is needed to survive globalisation and the increasingly tight competition among manufacturing firms.

Employees must first show innovative behaviour for innovation to occur in an organisation. Innovative behaviour includes the exploration, generation, championing and implementation of new processes and strategies for products, technologies, and work methods by employees to achieve innovative outcomes (Jong \& Hartog, 2010). Since the business environment is always unpredictable, innovation is required to respond swiftly in a competitive world (García-Sánchez, García-Morales, \& MartínRojas, 2018). Consequently, employees' decision-making logic is essential for innovative behaviour (Friedman \& Carmeli, 2017), as employees' judgments affect the overall performance or direction of an organisation. Therefore, appropriate actions are needed to achieve desired results.

The factors that influence the decision-making logic and innovative behaviour are linked to the values of individuals, as values guide employees' actions and behaviours (Léger-Jarniou \& Tegtmeier, 2017; Schwartz, 2003). Holland and Shepherd (2013) explored how entrepreneurs' personal values affect the way they exploit opportunities based on their decisions. Using the Schwartz value model, the authors found that differences in individual values influence entrepreneurial decisions.

Further, as stated by Holland and Shepherd (2013), individual values are largely dependent on how "one defines situations, considers alternatives, and ultimately chooses a course of action" (p. 338). Based on this definition, it is crucial to explore the values of individuals to understand the decision-making process.

\subsection{Schwartz value theory}

The Schwartz value theory serves as a guiding principle in individuals' lives, including in entrepreneurial decision making. The analysis of attitudes, opinions and actions can be best explained by values (Schwartz, 1992; 2003). Schwartz (1992) proposes a model comprising ten basic individual values (i.e. self-direction, stimulation, hedonism, benevolence, universalism, achievement, power, security, conformity, and tradition). These ten motivational domains form four higher-order value dimensions: self-transcendence, conservation, openness to change and self-enhancement.

Three motivational domains form openness to change (self-direction, stimulation, hedonism) and conservation (security, conformity, and tradition), respectively; while two motivational domains form self-transcendence (benevolence, universalism) and selfenhancement (achievement, power), respectively. Out of the four higher-order dimensions, two (self-enhancement and conservation) were excluded from this study in accordance with the parsimony principle, which advises against complicating a model with irrelevant variables or "multiplying entities beyond necessity" (Dieterle, 2001, p. 52).

The higher-order dimension of self-enhancement comprises the values of power and achievement. Predominantly, individuals with self-enhancement values are achievement-oriented and have a fear of failure (Pang, 2010). This fear results in these individuals' persistence with familiar strategies and routines. Sagiv and Schwartz (2007) also mentioned that people with a strong need to achieve typically set personal goals and strive to accomplish these goals. Such rigid adherence to strategies and fixed goals is in contrast with effectuation practices.

Individuals with self-enhancement values also place a high emphasis on power (Schwartz, 1992). They preserve and exert their dominant position as well as their control over people and resources by running through 
competitive analyses (Noordin, Zainuddin, Mail, \& Sariman, 2015). This resembles the causation approach of decision making, which is uncharacteristic of effectuation.

The conservation dimension consists of security, conformity, and tradition values that are more conventional and change-resistant (Schwartz, 2003). As most businesses face uncertainties, conservative individuals may be inclined to increase their safety and security (Bar-Tal, 2001). Hence, they avoid risky experimentations by following standard norms of behaviour. Such characteristics hinder the creative process, which is important for innovative behaviour to take place. Moreover, according to Schwartz and Bardi (2001), security and conformity values promote harmony by maintaining the status quo and weakening the motivation to innovate. Ultimately, creativity requires tolerance of ambiguity and risk-taking; therefore, "safety, caution, security, and prudence" values clearly clash with creativity (Kasof, Chen, Himsel, \& Greenberger, 2007, p. 109).

The aim of this study was to investigate individual values that are compatible with the effectuation approach and promote the innovative behaviour of employees. Previous studies have found that individuals with selfenhancement characteristics make decisions based on the causation logic (i.e. predetermined goals, predictions, profitmaximisation, competitive analysis) (Hepper, Gramzow, \& Sedikides, 2010; Tyszka, Cieślik, Domurat, \& Macko, 2011). Meanwhile, individuals with conservation values show a preference for preserving the status quo, which creates a mismatch with the logic of effectuation. Thus, individuals with such values would not thrive under effectuation. Based on this argument, this paper focused on two value dimensions that best enhance the success of effectuation: openness to change and self-transcendence.

\subsection{Openness to change values in effectuation}

The openness to change dimension includes selfdirection, stimulation, and hedonism values (Schwartz, 1992). Self-directed individuals show autonomy and control in their job decisions (Leskinen, 2011). This echoes the logic of effectuation, which states that "to the extent we can control the future, we do not need to predict it" (Sarasvathy, 2001, p.17). In another sense, self-directed individuals value the flexibility and control in the effectuation logic to minimise business uncertainties.
A high interest in novelty and change derives from the stimulation value. Stimulated individuals are usually curious and interested in exploring unfamiliar environments (Wilson \& Goldman-Rakic, 1994). Such novelty-seeking individuals are thus likely to be risk takers. In fact, effectuation does not endorse irresponsible risks and sticks to the budget allocated for losses. However, risk taking also involves non-monetary aspects. This includes risks in gaining new knowledge, new stakeholder relationships, and new challenges. Depending on the situation, these risks can be minimised as long as the stimulated individuals establish the amount they are willing to lose.

Uncertainties occur in MNCs due to constant pressures for survival along with constant changes in innovation demands. These challenges can be reduced if individuals are explorative in terms of turning obstacles into advantages. In this context, having the right values helps in embracing uncertainties. For instance, being self-directed enables individuals to be more daring and experimental (Schwartz, 2003). Generally, individuals who embrace openness to change are likely to fare better in such unstable environments.

\subsubsection{Self-transcendence in effectuation}

Self-transcendence reflects individuals who emphasise benevolence and universalism values (Schwartz, 1992). Benevolence describes the maintenance and protection of relationships, whereas universalism focuses on understanding, appreciating, and protecting people and nature. Overall, the self-transcendence dimension stresses tolerance and conflict avoidance to preserve the well-being of relationships (Kasof et al., 2007).

An unpredictable future can be managed by testing alternative solutions (experimentation) instead of forecasting events (Sarasvathy, 2001). Since experiments involve a lot of procedures and information, it is crucial for employees to be able to grasp additional and conflicting ideas (Chandler, DeTienne, McKelvie, \& Mumford, 2011). Employees need to be broadminded and tolerant in accepting information, which is represented by the universalism value (Kasof et al., 2007).

Employees who value benevolence view unexpected events in a positive light. By making the necessary adjustments, they transform challenges into opportunities and strive to enhance the welfare of the organisation (Deligianni, Voudouris, \& Lioukas, 2015). 
Universalist and benevolent employees are also concerned about stakeholders' interests (pre-commitment) and cope well with different opinions and views. In other words, self-transcendence involves placing importance on the needs of others (Schwartz, 2003). Thus, individuals with self-transcendence values preserve, enhance, understand, and appreciate relationships with stakeholders, as they play an important role in any venture. Given their high tolerance for uncertainties and ambiguities when dealing with stakeholders, such employees have the necessary characteristics for the implementation of effectuation.

Prior research has studied the impact of individual values on decision making (Costa, Tran, Turchi, \& Averbeck, 2014; Fritzsche \& Oz, 2007). However, no known studies have shown the link between individual values and effectuation. This study explored the individual value dimensions of openness to change and self-transcendence as they have been shown to fit in an effectual setting (Kasof et al., 2007; McKelvie et al., 2013). Hence, this study proposed that individual values influence the use of the effectuation decision-making process.

\section{Hypotheses Development and Theory}

Effectuation is said to work well in an innovative setting (Blekman, 2011). According to Hitt, Ireland, Camp and Sexton (2002), individuals actively seek interaction, which leads to new ideas and process innovations. These interactions are with stakeholders, namely self-selecting ones such as investors, customers, employees, and suppliers. It was also suggested by Kogut and Zander (1992) that knowledge increases by building social relationships. The combined current capabilities help create new knowledge, which encourages an innovative environment (Phipps \& Prieto, 2012).

The affordable loss aspect of effectuation encourages individuals to be cost savvy by coming up with creative ways of doing things at little to no cost. That being said, reasonable risks must be taken to achieve creativity (Shalley \& Gilson, 2004). Therefore, individuals endeavour to understand what they can afford to lose to generate ideas. By setting a limit on how much individuals are willing to invest and lose (affordable loss), the possibility of good ideas being eliminated at an early stage is avoided (Sun $\&$ Bisht, 2013). Thus, individuals have the flexibility to generate ideas as long as they are within the budget.
Flexibility in effectuation encourages individuals to overcome challenges by turning them into opportunities. By anticipating unforeseeable events, individuals generate new ideas to deal with unexpected situations. The study of Blauth, Mauer, and Brettel (2014) looked into the ability to perceive and exploit creative opportunities by embracing unexpected events. Their study showed a significant positive link between acknowledging the unexpected and creativity. Since effectuation allows individuals to find opportunities in unexpected challenges, it leads to innovative behaviour via the generation of ideas. Based on this explanation, it can be surmised that effectuation practices encourage innovative behaviour among employees.

Innovative behaviour is the implementation of ideas, which grants firms a competitive advantage and higher profitability (Roberts \& Amit, 2003). It has been shown in previous studies that innovation and firm performance have a positive relationship (Rosli \& Sidek, 2013; Zakaria, Abdullah, \& Yusoff, 2016). Ramamoorthy, Flood, Slattery, and Sardessai (2005) found that employees are likely to perform their job efficiently when they are in an environment that encourages innovative behaviour, thereby contributing to better company performance. Thus, innovative behaviour is predicted to lead to superior firm performance. On the other hand, the effectuation decision-making process allows employees to experiment, take risks, and seek opportunities in every obstacle within the allocated loss limit. This then permits them to show innovative behaviour (Roach, Ryman, \& Makani, 2016). In summary, the immediate outcome of effectuation is innovative behaviour, which subsequently improves firm performance. The following hypothesis was thus proposed:

H1: Innovative behaviour acts as a mediator between effectuation and firm performance.

Schwartz (2007) mentioned that values can predict human behaviour. This suggests that individual values play a significant role in predicting individuals' innovative behaviour. Although there have previously been studies on values and innovation (Blauth et al., 2014; Hitt et al., 2002; Phipps \& Prieto, 2012; Svensrud \& Åsvoll, 2012), there has been notably limited empirical research on individual values and innovative behaviour (Cooper, 2017).

Breuer and Ludeke-Freund (2015) adopted a value-based view of innovation and found that values lead to innovation by generating and implementing ideas by way of decision making. Therefore, values provide a sense of direction for innovation. This is consistent with 
previous literature that has found that individual values promote innovativeness (Cooper, 2017; Dollinger, Burke, \& Gump, 2007).

However, some studies have revealed an insignificant relationship between self-transcendence and innovative behaviour (Gorgievski, Ascalon, \& Stephan, 2011; Hirschi \& Fischer, 2013), while other studies have shown the opposite. Dollinger et al. (2007) argued that selftranscendence has a positive relationship with creativity, a sub-process of innovative behaviour. Another study from Kasof et al. (2007) discovered that universalism is positively correlated with creativity. However, this could be due to the participants in both studies being university students, whose objectives and goals may be different from those of working adults. These inconsistencies in the previously-discovered relationships show the need to introduce a mediator.

In fact, a few studies have indicated that a mediator is necessary for innovative behaviour to take place effectively (Park, Song, Lim, \& Kim 2014; Roach et al., 2016). For instance, Park et al. (2014) found that knowledge creation has a significant mediating effect between openness to change and creativity (a component of innovative behaviour). Thus, a mediator might explain the relationship between values and innovative behaviour. Further, Roach et al. (2016) stated that effectuation is an approach to managing the innovation process; therefore, effectuation should lead to innovation within a firm. Specifically, the authors found that SME employees with certain values (e.g. openness to change and self-transcendence) are more likely to use effectuation, which encourages them to engage more in innovative behaviour.

Since the extant research has established relationships between (a) values and decision making (Costa et al., 2014; Fritzsche \& Oz, 2007) and (b) decision making and innovative behaviour (Blauth et al., 2014; Svensrud \& Åsvoll, 2012), effectuation may act as a mediator between values and innovative behaviour. In short, effectuation may be one of the missing mechanisms that explain innovation in firms. Thus, it was proposed that:

H2: Effectuation acts as a mediator between openness to change and innovative behaviour.

H3: Effectuation acts as a mediator between self-transcendence and innovative behaviour.

The effectuation theory proposes that effectuation works in highly uncertain situations (Sarasvathy, 2001). Hence "innovative, flexible, and adaptive approaches" are crucial in such situations (Larson, White, Gober, \&
Wutich, 2015, p.12). Such uncertainties can be due to entry mode choices, internationalisation paths, market and technological uncertainties, employee commitment levels, and fast changing product development, especially in firms that are heavily involved in innovation projects (Galvez, Enjolras, Camargo, Boly, \& Claire 2018; Sniazhko, 2019). Therefore, the effectuation theory expounds how innovative behaviour can be cultivated among individuals working in MNCs based on their values.

Effectuation encourages employees to experiment with models and strategies whilst keeping in mind the risks involved. To stay within the budget, other methods are adopted, such as networking with partners. This theory also focuses on being agile during challenging situations. Innovative ideas and improvements are most likely to occur when individuals manage obstacles (York $\&$ Venkataraman, 2010) and turn them into opportunities to enhance firm performance.

This study examined whether and how individuals who embrace openness to change and self-transcendence values are more likely to use the effectuation decision-making process, which facilitates their innovative behaviour, and thereby improves firm performance. By including both people (individual values) and process (effectuation), this study aimed to show their complementary roles in driving innovative behaviour and firm performance. The proposed research framework is shown in Figure 1.

\section{Research Methods}

The objective of this study was to understand how people (individuals who embrace openness to change or self-transcendence values) and process (the effectuation decision-making process) complement each other in increasing innovative behaviour and firm performance. Therefore, it was crucial to target the key people involved in innovative work, such as supervisors, engineers, project managers, and technicians.

\section{I Measurements}

This study used an 11-item scale adapted from Schwartz's (2003) Portrait Values Questionnaire (PVQ21 ) to measure individual values ( 6 items for openness to change, $\alpha=0.75 ; 5$ items for self-transcendence, $\alpha=0.74$ ). A 10-item scale from de Jong and den Hartog (2010) was used to measure innovative behaviour $(\alpha=0.90)$, while a 13-item scale from Chandler et al. (2011) measured effectuation, comprising the dimensions of experimentation 


\section{H2 / H3}

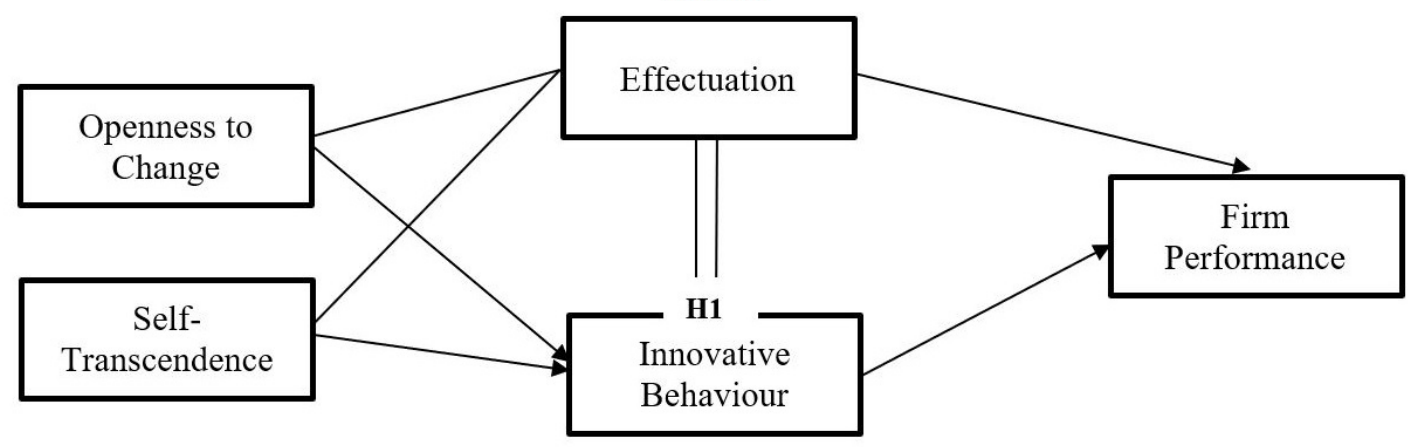

Figure 1. Research Framework

( 4 items, $\alpha=0.78$ ), affordable loss (3 items, $\alpha=0.85$ ), flexibility ( 4 items, $\alpha=0.70$ ), and pre-commitment ( 2 items, $\alpha=0.62$ ). Firm performance was measured with 2 items from Jaworski and Kohli (1993) $(\alpha=0.83)$, and a global item was used. All the items were rated on a 7-point Likert scale (see Appendix).

Self-assessments of firm performance by respondents are especially relevant when objective performance assessments are unattainable (Kellermanns, Eddleston, Sarathy, \& Murphy, 2012). Many studies have opted for subjective measures of business performance due to difficulties in obtaining objective financial data (Ahmad \& Zabri, 2016). Aside from confidentiality, available objective data may also be unreliable (Kraus, Harms, \& Schwarz, 2006), as managers may manipulate the data to avoid personal or corporate taxes (Dess \& Robinson, 1984; Sapienza, Smith, \& Gannon, 1988).

In the current unpredictable market, it is irrelevant to measure performance on a financial basis, as this no longer provides complete information about firms (Ahmad $\&$ Zabri, 2016). Firms with substantial commitments to $\mathrm{R} \& \mathrm{D}$, including product and market development for future growth, inevitably show losses or low profits in their financial statements (Covin \& Slevin, 1989). This may then be misinterpreted as poor performance. Hence, interpreting objective performance data can be tricky as the measures fail to take firms' development efforts into consideration, which results in inaccurate and misleading inferences. Based on these reasons, this study utilised subjective measures to assess firm performance.

\subsection{Data collection and sampling}

This study focused on employees working in manufacturing MNCs in Selangor, Malaysia. MNCs generally have operations in at least two different countries
(Mustapha, 2014). As such, MNCs are not classified by their number of employees; instead, they are classified by the number of actively operating countries, subsidiaries in foreign countries, revenues from global operations, or international stakeholders (Yunis, Jamali, \& Hashim, 2018). Here, MNCs "include all plants in which foreign equity shares are $50 \%$ or greater, including $50-50$ joint ventures which are often considered separately in official Malaysian publications" (Ramstetter \& Ahmad, 2009, p. 15). This study aimed to examine if the effectuation decision-making process is applicable to MNC employees who engage in innovative work. Therefore, the target population for this study was MNC employees in manufacturing MNCs in Selangor, Malaysia.

The snowball sampling technique was used, where invitations were sent through links on social media (Facebook, WhatsApp, and Telegram) and the recipients were encouraged to share the links with their acquaintances. The objectives of the research and the anonymity of respondents' information were explained in the invitation. The two criteria for employees to participate were: (a) holding a key role related to innovative work ideas and decision making and (b) having worked in a manufacturing MNC in Selangor for more than 2 years. These criteria were chosen due to the role of employees in solving customers' problems and contributing substantially to firms. Ultimately, 206 completed questionnaires were received.

\subsection{Data analysis strategy}

This study employed the partial least squares structural equation modelling software version 3.3.2 (PLS-SEM 3.3.2) to examine the interrelationships between the constructs in the research model. The twostep approach was applied by first verifying the validity 
and reliability of the measures (measurement model) and then the hypotheses were tested (structural model) (Hair, Hult, Ringle, \& Sarstedt, 2017). Specifically, the $\mathrm{R}$-squared values and effect sizes were assessed to evaluate endogenous variables, while t-values and significance levels (using the bootstrapping procedure) were used to evaluate structural path coefficients (Chin, 1998; Hair et al., 2017).

\subsection{Hierarchical component models}

Hierarchical component models involve testing measurement structures that contain two layers of constructs, i.e. higher-order components (HOCs) and lower-order components (LOCs) of the model. According to Chandler et al. (2011), the sub-dimensions of effectuation are considered as LOCs (i.e. experimentation, affordableloss, pre-commitments, and flexibility) and effectuation is considered to be a HOC. According to Schwartz et al. (2012), the sub-dimensions of openness to change (HOC) are self-direction, hedonism, and stimulation (LOCs). The self-transcendence (HOC) sub-dimensions are benevolence and universalism (LOCs). Overall, the model had three higher-order components (HOCs) that were type II (reflective-formative). The HOCs were openness to change, self-transcendence, and effectuation.

When analysing a higher-order construct, two points need to be considered: (1) the measurement model specification of the lower-order components and (2) the relationship between the higher-order component and its lower-order components (Hair et al., 2017). The current study applied the two-stage approach to HOC analysis (Cheah, Sarstedt, Ringle, Ramayah, \& Ting, 2019; Sarstedt, Hair, Cheah, Becker, \& Ringle, 2019). In the first stage, the LOCs of openness to change (i.e. self-direction, hedonism, stimulation), self-transcendence (i.e. universalism, benevolence), and effectuation (i.e. experimentation, affordable loss, pre-commitment, and flexibility) were assessed as reflective constructs. In the second stage, the latent variable scores of these LOCs were used as dimensions to establish the HOCs of openness to change, self-transcendence, and effectuation.

\section{Results}

\section{I Respondents' profile}

The descriptive analysis showed that out of the 206 respondents, $57.3 \%$ were males. Most of the respondents $(56.8 \%)$ were in the 26 to 35 age group. A majority of the respondents had a bachelor's degree $(60.7 \%)$ and were engineers (46.1\%). The demographics of the respondents are summarised in Table 1.

\subsection{Assessment of reflective measurement model}

The first step in the PLS-SEM analysis is to run the measurement model to obtain latent variable scores. Prior to obtaining the scores, this study discerned its reflective and formative measurements, which require different analyses. For the reflective model, internal consistency, convergent validity (Table 2 ), and discriminant validity (Table 3) were assessed. To analyse internal consistency and convergent validity, the outer loadings, Cronbach's alpha (CA), and average validity extracted (AVE) were calculated. As shown in Table 2, the indicators' outer loadings for all items exceeded the recommended value of 0.50 (Hair et al., 2017). The CA values of all constructs were above 0.70 , which indicated internal consistency. The AVE values ranged between 0.550 and 0.880 , which is greater than the cut-off value of 0.50 (Bagozzi \& Yi, 2012). Therefore, convergent validity was fulfilled.

Table 1

Summary of Respondents' Demographic Data

\begin{tabular}{lcc}
\hline Demographic Variable & $\begin{array}{c}\text { Frequency } \\
(\mathbf{n}=\mathbf{2 0 6})\end{array}$ & $\begin{array}{c}\text { Percentage } \\
(\mathbf{\%})\end{array}$ \\
\hline Gender & & \\
Male & 118 & 57.3 \\
Female & 88 & 42.7 \\
Age & & \\
$<26$ & 18 & 8.7 \\
$26-35$ & 117 & 56.8 \\
$36-45$ & 55 & 26.7 \\
$46-55$ & 14 & 6.8 \\
$>55$ & 2 & 1.0 \\
Education Level & & \\
Diploma & 25 & 12.1 \\
Bachelor & 125 & 60.7 \\
Master's & 56 & 27.2 \\
Length of Service & & \\
$2-3$ & 80 & 38.8 \\
$4-6$ & 72 & 35.0 \\
$7-9$ & 25 & 12.1 \\
$>10$ & 29 & 14.1 \\
Job Position & & \\
Technician & 25 & 12.1 \\
Supervisor & 53 & 25.7 \\
Project Manager & 33 & 16.0 \\
Engineer & 95 & 46.1 \\
\hline & &
\end{tabular}


Table 2

\section{Results of the Reflective Measurement Model}

\begin{tabular}{|c|c|c|c|c|c|c|}
\hline HOC & LOC & Indicator & Loading & CA & CR & AVE \\
\hline \multirow{6}{*}{$\begin{array}{l}\text { Openness to } \\
\text { Change }\end{array}$} & \multirow[t]{2}{*}{ Self-Direction } & OTC1 & 0.857 & \multirow[t]{2}{*}{0.627} & \multirow[t]{2}{*}{0.843} & \multirow[t]{2}{*}{0.728} \\
\hline & & OTC2 & 0.850 & & & \\
\hline & \multirow[t]{2}{*}{ Stimulation } & OTC3 & 0.879 & \multirow[t]{2}{*}{0.722} & \multirow[t]{2}{*}{0.878} & \multirow[t]{2}{*}{0.728} \\
\hline & & OTC4 & 0.890 & & & \\
\hline & \multirow{2}{*}{ Hedonism } & OTC5 & 0.836 & \multirow[t]{2}{*}{0.718} & \multirow{2}{*}{0.875} & \multirow[t]{2}{*}{0.778} \\
\hline & & OTC6 & 0.923 & & & \\
\hline \multirow{5}{*}{$\begin{array}{l}\text { Self- } \\
\text { Transcendence }\end{array}$} & \multirow[t]{2}{*}{ Benevolence } & ST1 & 0.884 & \multirow[t]{2}{*}{0.527} & \multirow[t]{2}{*}{0.804} & \multirow[t]{2}{*}{0.674} \\
\hline & & ST2 & 0.752 & & & \\
\hline & \multirow[t]{3}{*}{ Universalism } & ST3 & 0.836 & \multirow[t]{3}{*}{0.758} & \multirow[t]{3}{*}{0.861} & \multirow[t]{3}{*}{0.674} \\
\hline & & ST4 & 0.792 & & & \\
\hline & & ST5 & 0.834 & & & \\
\hline \multirow[t]{20}{*}{ Effectuation } & \multirow[t]{2}{*}{ Experimentation } & EX1 & 0.907 & \multirow[t]{2}{*}{0.777} & \multirow[t]{2}{*}{0.900} & \multirow[t]{2}{*}{0.818} \\
\hline & & EX4 & 0.901 & & & \\
\hline & \multirow[t]{3}{*}{ Affordable Loss } & AL1 & 0.915 & \multirow[t]{3}{*}{0.839} & \multirow[t]{3}{*}{0.903} & 0.757 \\
\hline & & AL2 & 0.883 & & & \\
\hline & & AL3 & 0.809 & & & \\
\hline & Flexibility & $\mathrm{F} 1$ & 0.832 & 0.811 & 0.876 & 0.639 \\
\hline & & F2 & 0.776 & & & \\
\hline & & F3 & 0.846 & & & \\
\hline & & F4 & 0.740 & & & \\
\hline & Pre-Commitment & PC1 & 0.934 & 0.864 & 0.936 & 0.880 \\
\hline & & PC2 & 0.942 & & & \\
\hline & Innovative & IB2 & 0.542 & 0.895 & 0.916 & 0.550 \\
\hline & Behaviour & IB3 & 0.789 & & & \\
\hline & & IB4 & 0.795 & & & \\
\hline & & IB5 & 0.794 & & & \\
\hline & & IB6 & 0.644 & & & \\
\hline & & IB7 & 0.724 & & & \\
\hline & & IB8 & 0.775 & & & \\
\hline & & IB9 & 0.803 & & & \\
\hline & & IB10 & 0.766 & & & \\
\hline
\end{tabular}

Note: EX2, EX3, and IB1 were removed due to low loadings $(<0.4) . \mathrm{HOC}=$ Higher-order component; LOC = Lower-order component; $\mathrm{CR}=$ Composite reliability; $\mathrm{CA}=$ Cronbach's alpha; $\mathrm{AVE}=$ Average variance extracted

Table 3

\section{Results of HTMT for the Reflective Measurement Model}

\begin{tabular}{|c|c|c|c|c|c|c|c|c|c|}
\hline & AL & Bene & Exp & Flexi & Hedo & IB & PC & SD & Stimu \\
\hline Bene & 0.259 & & & & & & & & \\
\hline Exp & 0.330 & 0.066 & & & & & & & \\
\hline Flexi & 0.608 & 0.227 & 0.610 & & & & & & \\
\hline Hedo & 0.124 & 0.105 & 0.129 & 0.275 & & & & & \\
\hline IB & 0.445 & 0.122 & 0.536 & 0.618 & 0.163 & & & & \\
\hline PC & 0.444 & 0.126 & 0.501 & 0.529 & 0.212 & 0.410 & & & \\
\hline SD & 0.157 & 0.050 & 0.338 & 0.251 & 0.089 & 0.443 & 0.160 & & \\
\hline Stimu & 0.140 & 0.092 & 0.403 & 0.400 & 0.426 & 0.410 & 0.233 & 0.474 & \\
\hline Uni & 0.133 & 0.691 & 0.205 & 0.299 & 0.380 & 0.206 & 0.303 & 0.205 & 0.225 \\
\hline
\end{tabular}

Note: Average variances extracted (AVEs) are shown (in bold) on the diagonal. $\mathrm{AL}=$ Affordable Loss; Bene $=\mathrm{Benevolence;} \mathrm{Exp=}$ Experimentation; Flexi $=$ Flexibility; Hedo $=$ Hedonism; $\mathrm{IB}=$ Innovative Behaviour $\mathrm{PC}=$ Pre-Commitment; $\mathrm{SD}=\mathrm{Self}-\mathrm{Direction}$; Stimu $=$ Stimulation; Uni $=$ Universalism. 
Table 3 depicts the discriminant validity of the constructs based on the heterotrait-monotrait ratio of correlations (HTMT) technique (Henseler, Ringle, \& Sarstedt, 2015). The results showed that the values fulfilled the HTMT criterion (Kline, 2011). Hence, discriminant validity was established for the study constructs.

\subsection{Assessment of formative measurement model}

Table 4 shows the formative measurement model results. The assessment of the formative construct, firm performance, comprised three steps. First, the redundancy analysis of the formative construct indicated that the path coefficient of the global item (0.745) was above the threshold value of 0.7 . This verified that the construct had sufficient degrees of convergent validity (Sarstedt, Wilczynski, \& Melewar, 2013). Second, the variance inflation factor (VIF) was measured to identify if the predictors were highly correlated (multicollinearity). The items demonstrated VIF values lower than 3.33, hence multicollinearity issues were absent (Diamantopoulos \& Siguaw, 2006). Third, the significances and outer weights of the items showed that they were significant $(\mathrm{p}<0.05)$.

Additionally, the model fit was also examined by testing the standardised root mean square residuals
(SRMRs). Anything below the threshold value of 0.080 is considered a good fit (Hu \& Bentler, 1999). The model in the current study obtained an SRMR value of 0.071 , which proved that the data fit the model.

\subsection{Assessment of HOC}

The two-stage HOC analysis involved first evaluating the latent variable scores for the LOCs, which were used as manifest variables for the HOCs. Table 5 presents the HOCs for the reflective-formative measurement model (openness to change, self-transcendence, and effectuation). The significances and outer weights of the constructs showed that most items achieved significance $(\mathrm{p}<0.05)$. However, some items (hedonism, benevolence, affordable loss, and pre-commitment) were insignificant ( $p>0.05$ ). Nevertheless, these dimensions were retained due to the theoretical support (Hair et al., 2017).

\subsection{Assessment of structural model}

Table 6 shows that all the inner VIF values were less than 3.33; hence, multicollinearity issues were absent from the model (Diamantopoulos \& Siguaw, 2006). Next, the bootstrapping results were evaluated to check the significance of the path coefficients. Prior to running the bootstrapping procedure, subsamples of 5000 were

Table 4

\section{Results of the Formative Measurement Model}

\begin{tabular}{lcccccc}
\hline Construct & Items & $\begin{array}{c}\text { Convergent } \\
\text { Validity (with } \\
\text { global item) }\end{array}$ & Outer Weight & VIF & t-value & p-value \\
\hline Firm Performance & FP1 & 0.745 & 0.731 & 1.349 & 12.654 & 0.000 \\
& FP2 & & 0.405 & 1.349 & 5.726 & 0.000 \\
\hline
\end{tabular}

Note: $\mathrm{VIF}=$ Variance Inflation Factor

Table 5

\section{Assessment of Higher-Order Constructs}

\begin{tabular}{llcccc}
\hline \multicolumn{1}{c}{ HOC } & \multicolumn{1}{c}{ LOC } & Weights & t-value & p-value & Outer VIF \\
\hline Openness to Change & Self-Direction & 0.368 & 3.852 & 0.026 & 1.123 \\
& Stimulation & 0.683 & 4.529 & 0.000 & 1.250 \\
& Hedonism & 0.312 & 1.253 & 0.102 & 1.123 \\
Self-Transcendence & Benevolence & 0.093 & 0.035 & 0.759 & 1.251 \\
& Universalism & 0.955 & 6.629 & 0.000 & 1.251 \\
Effectuation & Experimentation & 0.387 & 4.117 & 0.001 & 1.381 \\
& Affordable Loss & 0.095 & 0.829 & 0.416 & 1.399 \\
& Flexibility & 0.595 & 4.779 & 0.000 & 1.687 \\
& Pre-Commitment & 0.174 & 0.860 & 0.187 & 1.380 \\
\hline
\end{tabular}

Note: $\mathrm{HOC}=$ Higher-Order Component, LOC = Lower-Order Component 
set with no sign changes. As for the confidence interval, the bias-corrected and accelerated ( $\mathrm{BCa}$ ) bootstrapping procedure was chosen. Also, since this study emphasised mediation, a two-tailed test was used with a significance level of 0.05 (Hair et al., 2017; Henseler et al., 2015).

Table 7 shows the significances (t-values) and relevance of the significant relationships. Based on Table 7 , it is apparent that openness to change $(B=0.352 ; 0.220)$ was a stronger predictor of effectuation and innovative behaviour than self-transcendence $(~(=0.172 ;-0.008)$. Effectuation had a strong effect on innovative behaviour $(B=0.502)$ than on firm performance $(B=0.149)$, while innovative behaviour had a strong effect on firm performance $(\beta=0.288)$. The results also showed that the variance explained $\left(R^{2}\right)$ for innovative behaviour was 0.381 , which is substantial. On the other hand, the $\mathrm{R}^{2}$ values for effectuation (0.183) and firm performance (0.156) were moderate (Cohen, 1988).

In addition to these measures, effect size $\left(f^{2}\right)$ and predictive relevance $\left(\mathrm{Q}^{2}\right)$ were reported. Cohen's (1988) guideline was used to measure the degree of effect sizes, which are small (0.02), medium (0.15) and large (0.35). Accordingly, the effect size $\left(f^{2}\right)$ for openness to change and self-transcendence in relation to effectuation (0.142; $0.034)$ and innovative behaviour $(0.066 ; 0.000)$ were small. The result also indicated that innovative behaviour had a small effect (0.065) on firm performance. Lastly, the effect of effectuation on innovative behaviour was found to be medium (0.337) and its effect on firm performance was found to be small (0.017) (Cohen, 1988). Overall, the figures suggest that the effectuation decision-making logic played the most substantial role in the structural model, indicated by the highest $\mathrm{f}^{2}$ value (0.337).

Using a blindfolding procedure, this study then examined the predictive relevance of the model. Table 7 shows the $\mathrm{Q}^{2}$ values for innovative behaviour $\left(\mathrm{Q}^{2}=0.203\right)$, firm performance $\left(\mathrm{Q}^{2}=0.103\right)$ and effectuation $\left(\mathrm{Q}^{2}=0.078\right)$. All values were above 0 , which implies that the model had sufficient predictive relevance (Hair et al., 2017).

This study also analysed the demographic information as control variables (age, position, and experience). These control variables were included in the structural model; however, none of them had any explanatory influence on effectuation. The corresponding results are presented in Figure 2.

\subsection{Mediation analysis}

Upon analysing the measurement model and structural model, this study ran the bootstrapping procedure in PLS-SEM to identify the significance of the direct relationships ( $\mathrm{t}$-values) prior to the mediation analysis. After bootstrapping, this study proceeded to analyse the indirect effect results (Table 8).

Table 6

\section{Lateral Collinearity Assessment}

\begin{tabular}{|c|c|c|c|}
\hline & Effectuation & Firm Performance & Innovative Behaviour \\
\hline Self-Transcendence & 1.060 & & 1.086 \\
\hline Openness to Change & 1.067 & & 1.190 \\
\hline Effectuation & & 1.515 & 1.207 \\
\hline Innovative Behaviour & & 1.515 & \\
\hline
\end{tabular}

Table 7

Path Coefficients in the Structural Model

\begin{tabular}{|c|c|c|c|c|c|c|}
\hline Relationship & $\begin{array}{c}\text { Path } \\
\text { Coefficient }\end{array}$ & $\begin{array}{c}\text { Std. } \\
\text { Error }\end{array}$ & t-value & $\mathbf{R}^{2}$ & $\mathbf{f}^{2}$ & $\mathbf{Q}^{2}$ \\
\hline Effectuation $\rightarrow$ Firm Performance & 0.149 & 0.086 & 1.737 & & 0.017 & \\
\hline Effectuation $\rightarrow$ Innovative Behaviour & 0.502 & 0.051 & $9.776^{* *}$ & 0.381 & 0.337 & 0.203 \\
\hline Innovative behaviour $\rightarrow$ Firm Performance & 0.288 & 0.084 & $3.428^{* *}$ & 0.156 & 0.065 & 0.103 \\
\hline Openness to Change $\rightarrow$ Innovative Behaviour & 0.220 & 0.067 & $3.271^{* *}$ & & 0.066 & \\
\hline Openness to Change $\rightarrow$ Effectuation & 0.352 & 0.060 & $5.882^{* *}$ & 0.183 & 0.142 & 0.078 \\
\hline Self-Transcendence $\rightarrow$ Innovative Behaviour & -0.008 & 0.060 & 0.128 & & 0.000 & \\
\hline Self-Transcendence $\rightarrow$ Effectuation & 0.172 & 0.069 & $2.478^{* *}$ & & 0.034 & \\
\hline
\end{tabular}

Note: ${ }^{* *} \mathrm{p}<0.01$ 


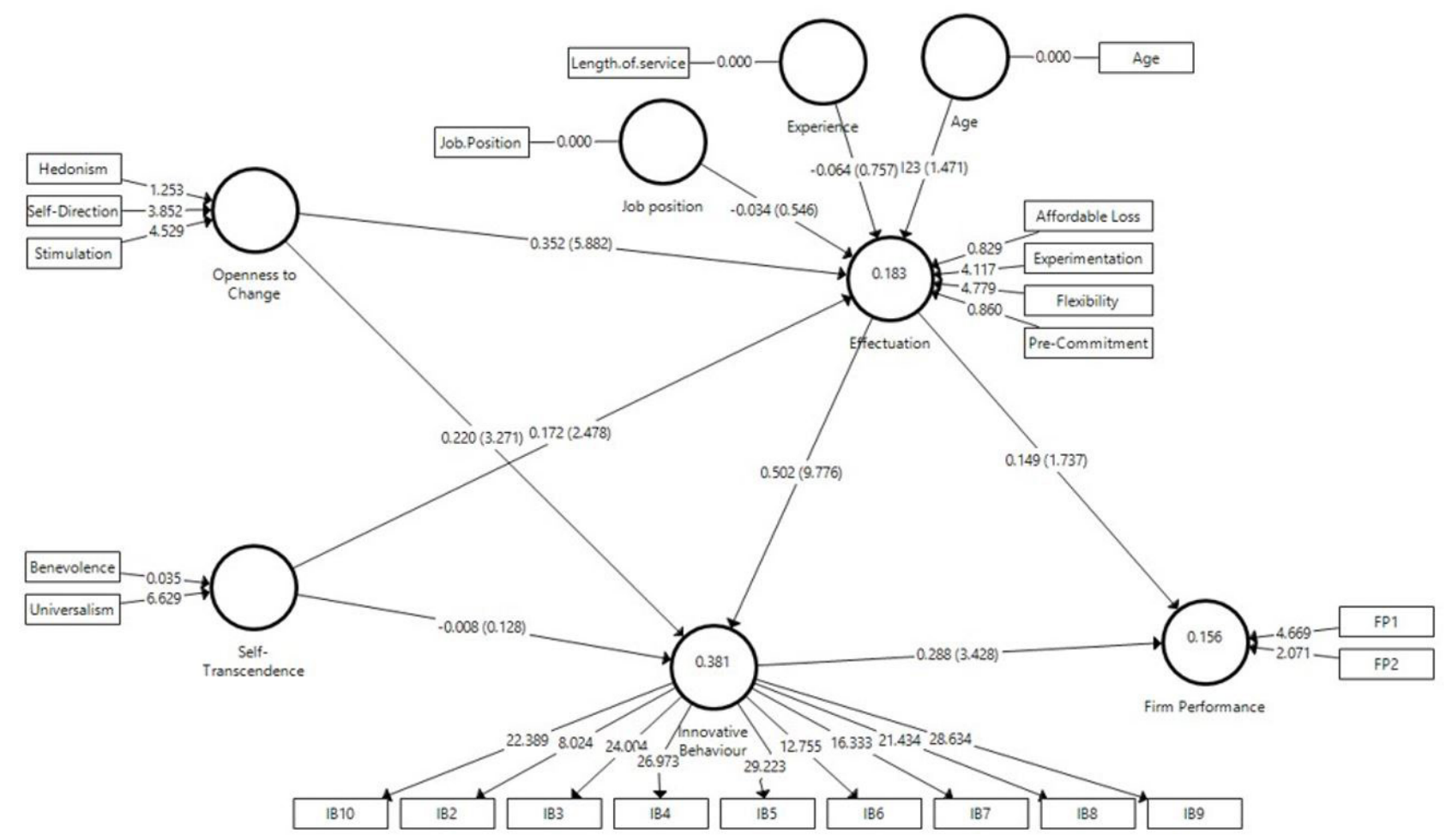

Figure 2. Partial Least Square-Structural Equation Modelling (PLS-SEM) model

Table 8

\section{Hypotheses Testing Results for Mediation}

\begin{tabular}{|c|c|c|c|c|c|c|c|c|}
\hline & \multirow{2}{*}{ Constructs } & \multirow{2}{*}{ Std. Beta } & \multirow{2}{*}{ Std. Error } & \multirow{2}{*}{ t-value } & \multirow{2}{*}{ p-value } & Confiden & rval (BC) & \multirow{2}{*}{ Results } \\
\hline & & & & & & \multicolumn{2}{|c|}{ LL UL } & \\
\hline H1 & $\begin{array}{l}\text { Effectuation } \\
>\text { IB > FP }\end{array}$ & 0.145 & 0.046 & 3.152 & 0.002 & 0.064 & 0.242 & Supported \\
\hline H2 & OTC $>$ Effectuation & & & & & & & \\
\hline & $>$ IB & 0.177 & 0.033 & 5.321 & 0.000 & 0.125 & 0.254 & Supported \\
\hline H3 & $\begin{array}{l}\text { ST > Effectuation } \\
>\text { IB }\end{array}$ & 0.086 & 0.038 & 2.289 & 0.023 & 0.020 & 0.165 & Supported \\
\hline
\end{tabular}

Note: $\mathrm{p}<0.05$, t-value $>1.96 ; \mathrm{BC}=$ Bias Correlated; $\mathrm{LL}=$ Lower Level; $\mathrm{UL}=$ Upper Level; $\mathrm{IB}=$ Innovative Behaviour; OTC $=$ Openness to Change; ST = Self-Transcendence; FP = Firm Performance.

The bootstrapping analysis revealed that all three indirect effects, $\beta=0.145, \beta=0.177$, and $\beta=0.086$, were significant, with $\mathrm{t}$-values of $3.152,5.321$, and 2.289, respectively. The bias-correlated $95 \%$ confidence intervals of the indirect effects $(\mathrm{LL}=0.064, \mathrm{UL}=0.242 ; \mathrm{LL}=0.125$, $\mathrm{UL}=0.254 ; \mathrm{LL}=0.020, \mathrm{UL}=0.165)$ indicated that there was mediation since the results did not straddle a zero value between the lower and upper limits (Preacher $\&$ Hayes, 2008). As such, it was concluded that the mediating effects were statistically significant.

Although the bootstrapping analysis revealed that there was mediation in all three relationships, the types of mediation effect were unknown. There are three types of mediation: complementary, competitive and indirect-only mediation (Hair et al., 2017; Zhao, Lynch, $\&$ Chen, 2010). Complementary mediation occurs when the indirect effect and direct effect are significant and point in the same direction. When both indirect and direct effects are significant but point in the opposite direction, the mediation is considered to be competitive. Indirect-only mediation occurs when the indirect effect is significant but the direct effect is not. To extract more information on the mediation effect, this study went on to determine the significance of the indirect effect and 
direct effect of the three mediation hypotheses $(\mathrm{H} 1, \mathrm{H} 2$ and H3) (Hair et al., 2017). The results are summarized in Table 9.

\section{Discussion}

Tables 8 and 9 reveal that all three mediation hypotheses were supported, where two mediations were found to be indirect-only and one was found to be complementary. The first hypothesis (H1) indicated innovative behaviour as an indirect-only mediator between effectuation and firm performance. This shows that when a good decision-making process (effectuation) is used, innovative behaviour will follow, which is a crucial factor in high firm performance. That is, effectuation alone does not lead to performance whereby effectuation decision making has to be used in relation to the development of innovation plans and actions for performance to take place. Therefore, when sound innovative plans and decisions are made via effectuation, high performance is achieved as 'implementation-oriented behaviour' is activated by the effectuation decision-making process (Jong \& Hartog, 2010). Thus, the use of the effectuation logic translates into high firm performance indirectly through the incorporation of innovative behaviour alone. As such, effectuation directly and indirectly leads to innovative behaviour.

As for $\mathrm{H} 2$, the result showed that effectuation serves as a complementary mediator between openness to change and innovative behaviour. Prior studies have confirmed a significant relationship between employees' openness to change and creativity (Anderson, Potočnik, \& Zhou, 2014; George \& Zhou, 2001). This shows that, along with openness to change values, employees' ways of thinking, deciding, and acting play a vital role in encouraging innovative behaviour. The outcome of this study also reaffirms the findings of Park et al. (2014), who claimed that a mechanism is needed for individuals to achieve desirable behaviour. In this case, the mechanism is the use of the effectuation decision-making process to trigger the adoption of innovative behaviour. That is, the use of effectuation decision making further enhances the innovative behaviour among individuals who are open to change. In other words, individuals who are open to change are naturally already more innovative, but incorporating effectuation decision making will enhance their innovative capabilities even more.

The result for $\mathrm{H} 3$ affirmed that effectuation acts as an indirect-only mediator between self-transcendence and innovative behaviour. The extant literature has shown insignificant and negative relationships between selftranscendence and innovative behaviour (Gorgievski et al., 2011; Hirschi \& Fischer, 2013). However, this relationship appears to be significant when effectuation is introduced as a mediator, where self-transcendence has an indirect effect on innovative behaviour through effectuation. In other words, self-transcendence values alone are not enough to spark innovation. Employees with self-transcendence values may exhibit high innovative behaviour, provided that they adopt the effectuation process in their decision making. In brief, the logic of effectuation encourages self-transcendent individuals to innovate.

The current findings illustrate that the right blend of people (those with openness to change or self-transcendence values) and process (the effectuation decision-making process) enhances innovative behaviour and firm performance. Since effectuation fits unstable environments with many uncertainties, adopting effectuation is a better alternative in such environments to achieve

\section{Table 9}

\section{Determining the Type of Mediation Effect}

\begin{tabular}{llcccl}
\hline \multicolumn{1}{c}{ Hypothesis } & \multicolumn{1}{c}{ Constructs } & $\begin{array}{c}\text { Path } \\
\text { Coefficient }\end{array}$ & t-value & Results & Type of Mediation \\
\hline H1 & Effectuation $\rightarrow$ IB & 0.502 & 9.776 & Significant & \\
Effectuation & IB $\rightarrow$ FP & 0.288 & 3.428 & Significant & \\
$>$ IB $>$ FP & Effectuation $\rightarrow$ FP & 0.149 & 1.737 & Not Significant & Indirect-only mediation \\
H2 & OTC $\rightarrow$ Effectuation & 0.352 & 5.882 & Significant & \\
OTC $>$ & Effectuation $\rightarrow$ IB & 0.502 & 9.776 & Significant & \\
Effectuation $>$ IB & OTC $\rightarrow$ IB & 0.220 & 3.271 & Significant & Complementary (Partial mediation) \\
H3 & ST $\rightarrow$ Effectuation & 0.172 & 2.478 & Significant & \\
ST $>$ & Effectuation $\rightarrow$ IB & 0.502 & 9.776 & Significant & \\
Effectuation $>$ IB & ST $\rightarrow$ IB & -0.008 & 0.128 & Not Significant & Indirect-only mediation \\
\hline
\end{tabular}

Note: IB = Innovative Behaviour; OTC = Openness to Change; ST = Self-Transcendence; FP = Firm Performance 
desirable outcomes (high innovative behaviour and firm performance). However, a majority of Malaysian firms adopt the causation way of making decisions (prediction, planning, structured innovation, competitor analysis) (GE Global Barometer, 2014), possibly because the awareness of effectuation is still low in Malaysia.

Effectuation has been around for two decades; however, it is almost unheard of in Malaysia. Therefore, this study intended to highlight the efficacy of effectuation in an environment with high uncertainty. Effectuation can improve innovative behaviour and firm performance among manufacturing MNCs in Malaysia.

\section{I Managerial implications}

The findings of this study have three implications for managers. First, the outcomes can serve as a guideline for organisations to provide training on the effectuation decision-making logic. Effectuation has been shown to work well in an innovative setting (Roach et al., 2016), which fits the case of manufacturing MNCs as they constantly require innovation in processes and products. MNCs could thus encourage employees to make decisions by experimenting with the resources and networks they have as well as by keeping an open mind to see opportunities in obstacles. It is important for employees adopting this logic to set a budget regarding how much they can afford to lose to avoid greater losses. Additionally, the results indicate that individuals with openness to change and selftranscendence values achieve innovative behaviour with the help of effectuation. As such, encouraging employees to adopt effectuation in MNCs increases their innovative behaviour due to the flexibility of the effectuation logic.

Second, this study found that values impact innovative behaviour, which subsequently leads to better firm performance. Hiring candidates with openness to change or self-transcendence values could improve firm performance through their innovative behaviour, provided they are trained to use effectuation and innovative techniques. Thus, firms could use value instruments in the process of selecting new staff.

Third, a firm's organisational culture should be fit for the effectuation process, since effectuation requires flexibility, job authority, and autonomy. Effectuation can be cultivated within an organisational culture by having leaders endorse and use it visibly in the firm. Furthermore, innovative behaviour is a core ingredient of firm performance; thus, an organisational culture should support innovative behaviour by celebrating small innovations. Concisely, the organisational culture should allow flexibility and innovation for individuals to make effective decisions that lead to innovative behaviour and, subsequently, better firm performance.

\subsection{Theoretical implications}

This study contributes to the value-behaviour literature by providing empirical evidence on mediators that link values to behaviour. The preceding literature has shown that self-transcendence and innovative behaviour have insignificant or negative relationships (Gorgievski et al., 2011; Hirschi \& Fischer, 2013). In contrast to the literature, this study uncovered an underlying mechanism that transformed the aforementioned value-behaviour relationship into a positive one. Thus, the study enriches the literature by revealing a mediator that establishes and explains the positive relationship between self-transcendence and innovative behaviour.

Innovation and uncertainty are integral parts of the innovation process (Jalonen, 2011), because the sources, opportunities, and outcomes of innovation are very much unpredictable (Kanter, 1985). As such, an efficient approach (effectuation) is needed to deal with such situations. The effectuation theory is a form of decision-making logic which assumes that the future is largely unpredictable, especially in organisations facing multiple uncertainties. However, this can be controlled through human actions. To this end, this study found the effectuation theory (Sarasvathy, 2001) to be applicable to manufacturing MNCs and that it encourages innovative behaviour. Effectuation works well under uncertainty by embracing obstacles and turning them into opportunities. Hence, this study contributes towards the expansion of the effectuation theory as a method of achieving innovative behaviour among employees.

This study also found that the personal values proposed by Schwartz (2003) are valid predictors of effectuation and innovative behaviour. Specifically, the values of openness to change and self-transcendence support the effectuation decision-making process and subsequently drive innovative behaviour and firm performance. This study therefore provides additional evidence on the valuebehaviour relationship by introducing two mediators (effectuation and innovative behaviour) that strengthen the link between individual values and behaviour. 
The extant literature has focused on the application of effectuation in small and medium-sized enterprises and start-ups (Frederiksen \& Brem, 2017; Lepistö et al., 2019). These prior studies find that effectuation suits smaller firms due to the challenges faced by their industry (Brettel et al., 2012; McKelvie et al., 2013). However, recent studies imply that effectuation is gaining recognition in established firms (Matalamäki, 2017; Werhahn, Mauer, Flatten, \& Brettel, 2015). Manufacturing MNCs face highly uncertain conditions that require fast and flexible decision making, which requires the use of the effectuation logic to promote innovative behaviour and firm performance. This study thus extends the effectuation theory to the context of manufacturing MNCs.

\subsection{Limitations and future research directions}

The limitations of this study provide the bases for further empirical research. First, this study only looked at manufacturing MNCs in Selangor, Malaysia, thus limiting its generalisation. Future researchers could compare decision-making processes across industries such as services and construction. Examining each industry's likelihood of practising effectuation would unearth a new paradigm in the literature.

The literature acknowledges that examining both decision-making logics (effectuation and causation) paints a better picture of the current situation in MNCs. Effectuation is not superior to causation, but rather it is an alternative decision-making logic. Firms could use both logics effectively in different contexts. This study only evaluated effectuation; therefore, it is not able to identify the contexts that are suitable for each logic. It would be interesting for future studies to explore the willingness of organisations to allow both logics to co-exist.

The next limitation relates to the poor explanatory power of effectuation and innovative behaviour, which is $38 \%$ and $18 \%$, respectively. This suggests that $62 \%$ and $82 \%$ of the variance in these constructs were due to unexplained factors. Future studies should thus probe the remaining individual values (self-enhancement and conservation) to close this gap. Investigating other factors that support the adoption of effectuation as a business strategy would reveal new insights as well. This could be done by interviewing upper management to understand their views on effectuation from various angles. Lastly, it is vital to understand employee-leader or employee-manager relationships in terms of effectuation. Thus, identifying suitable leadership styles that cultivate effectuation and innovative behaviour would add value to the literature on effectuation.

\section{Conclusion}

In addressing the question "What are the roles of people (individual values) and process (effectuation) in advancing firm performance?" this study found that the right blend of people (those who embrace openness to change or self-transcendence values) and process (the effectuation decision-making process) is a way to enhance firm performance. The effectuation decision-making process was revealed to be an underlying mechanism behind the value-performance relationship. Further analysis found that the effect size ( $\left.f^{2}\right)$ of process (effectuation) was higher than that of people (individual values). Effectuation was also shown to fully mediate in the relationship between self-transcendence and innovative behaviour, indicating that an absence of effectuation would impede firm performance. Therefore, this study contributes to the literature by (a) analysing the roles played by people and process in optimising firm performance and (b) identifying effectuation and innovative behaviour as mechanisms that link individual values to firm performance. In summary, to enhance firm performance, firms should consider applying the effectuation decision-making process to increase innovative behaviour. Firms should also hire individuals who display openness to change or self-transcendence values to better implement the effectuation process.

\section{References}

Aboelmaged, M. G. (2012). Harvesting organizational knowledge and innovation practices: An empirical examination of their effects on operations strategy. Business Process Management Journal, 18(5), 712-734.

Ahmad, K., \& Zabri, S. M. (2016). The application of non-financial performance measurement in Malaysian manufacturing firms. Procedia Economics and Finance, 35(2016), 476-484.

Ahmic, A., Sunje, A., \& Kurtic, E. (2016). The influence of top managers' personal values on sustainability of SMEs in developing countries. Journal of Corporate Governance, Insurance and Risk Management, 3(1), 27-49. 
Anderson, N., Potočnik, K., \& Zhou, J. (2014). Innovation and creativity in organisations: A state-of-the-science review, prospective commentary, and guiding framework. Journal of Management, 40(5), 1297-1333.

Arasa, R., \& K'Obonyo, P. (2012). The relationship between strategic planning and firm performance. International Journal of Humanities and Social Science, 2(22), 201-213.

Bagozzi, R. P., \& Yi, Y. (2012). Specification, evaluation, and interpretation of structural equation models. Journal of the academy of Marketing Science, 40(1), 8-34.

Barrett, M. A., \& Moores, K. (2012). New theoretical perspectives on family business entrepreneurial behavior. In Understanding Family Businesses (pp. 271-288). New York, NY: Springer.

Bar-Tal, D. (2001). Why does fear override hope in societies engulfed by intractable conflict, as it does in the Israeli society? Political Psychology, 22(3), 601-627.

Berends, H., Jelinek, M., Reymen, I., \& Stultiëns, R. (2014). Product innovation process in small forms: Combining entrepreneurial effectuation and managerial causation. Journal of Product Innovation Management, 31(3), 616-635.

Blauth, M., Mauer, R., \& Brettel, M. (2014). Fostering creativity in new product development through entrepreneurial decision making. Creativity and Innovation Management, 23(4), 495-509.

Blekman, T. (2011). Corporate effectuation: What managers should learn from entrepreneurs. Stanford, CA: Academic Service.

Brenner, B., \& Ambos, B. (2013). A question of legitimacy? A dynamic perspective on multinational firm control. Organization Science, 24(3), 773-795.

Brettel, M., Bendig, D., Keller, M., Friederichsen, N., \& Rosenberg, M. (2014). Effectuation in manufacturing: How entrepreneurial decision-making techniques can be used to deal with uncertainty in manufacturing. Procedia CIRP, 17, 611-616.

Brettel, M., Mauer, R., Engelen, A., \& Küpper, D. (2012). Corporate effectuation: entrepreneurial action and its impact on $\mathrm{R} \& \mathrm{D}$ project performance. Journal of Business Venturing, 27(2), 167-184.

Breuer, H. \& Lüdeke-Freund, F. (2015). Values-based innovation framework -- innovating by what we care about paper presented at the XXVI ISPIM Conference 2015 - Shaping the frontiers of innovation management, Budapest, Hungary, 26. Retrieved from https://poseidon01. ssrn.com/delivery.php? ID=439105103119120122093082 118085025123000005036021011004064069026091104 014064102085075106063016032058001000023091074 08512207800101603507500302100306908702600506412 011601807709511309009711210211911702312708711509 401901806710007608609110409412600709 8011096\&EXT $=$ pdf\&INDEX=TRUE

Chandler, G. N., DeTienne, D. R., \& Mumford, T. V. (2007). Causation and effectuation: Measurement development and validation. Frontiers of Entrepreneurship Research, 27(13), 375-390.

Chandler, G. N., DeTienne, D. R., McKelvie, A., \& Mumford, T. V. (2011). Causation and effectuation processes: A validation study. Journal of Business Venturing, 26(3), 375-390.

Cheah, J. H., Sarstedt, M., Ringle, C. M., Ramayah, T., \& Ting, H. (2019). Convergent validity assessment of formatively measured constructs in PLS-SEM: On using single-item versus multi-item measures in redundancy analyses. International Journal of Contemporary Hospitality Management, 30(11), 3192-3210.

Chin, W. W. (1998). The partial least squares approach to structural equation modeling. Modern methods for business research, 295(2), 295-336.

Cohen, J. (1988). Statistical power analysis for the behavioural sciences (2nd ed.). Hillsdale, NJ: Lawrence Earlbaum Associates.

Cooper, N. E. D. (2017). The Relationship between personal values, organisational formalization and employee work outcomes of compliance and innovation. International Journal of Manpower, 38(2), 274-287.

Corry, S., \& Cormican, K. (2019). Towards innovation in multinational corporation subsidiaries: Development of an instrument to select and evaluate value driven 
strategies. Journal of technology management \& innovation, 14(1), 25-33.

Costa, V. D., Tran, V. L., Turchi, J., \& Averbeck, B. B. (2014). Dopamine modulates novelty seeking behaviour during decision making. Behavioural neuroscience, 128(5), 556-566.

Covin, J. G., \& Slevin, D. P. (1989). Strategic management of small firms in hostile and benign environments. Strategic Management Journal, 10(1), 75-87.

Crespo, C. F., Griffith, D. A., \& Lages, L. F. (2014). The performance effects of vertical and horizontal subsidiary knowledge outflows in multinational corporations. International Business Review, 23(5), 993-1007.

Daniel, E. M., Domenico, M. D., \& Sharma, S. (2015). Effectuation and home-based online business entrepreneurs. International Small Business Journal, 33(8), 799-823.

Darroch, J. (2005). Knowledge management, innovation and firm performance. Journal of Knowledge Management, 9(3), 101-115.

Deligianni, I., Voudouris, I., \& Lioukas, S. (2015). Do effectuation processes shape the relationship between product diversification and performance in new ventures? Entrepreneurship Theory and Practice, 41(3), 349-377.

Dess, G. G., \& Robinson, R. B. (1984). Measuring organizational performance in the absence of objective measures: The case of the privately-held firm and conglomerate business unit. Strategic Management Journal, 5(3), 265-273.

Diamantopoulos, A., \& Siguaw, J. A. (2006). Formative versus reflective indicators in organisational measure development: A comparison and empirical illustration. British Journal of Management, 17(4), 263-282.

Dieterle, J. M. (2001). Ockham's razor, encounterability, and ontological naturalism. Erkenntnis (1975-), 55(1), $51-72$.

Dollinger, S. J., Burke, P. A., \& Gump, N. W. (2007). Creativity and values. Creativity Research Journal, 19(23), 91-103.
Donassolo, P. H., \& Matos, C. A. D. (2014). The predictors of sales performance: a study with wholesale sellers. Revista Brasileira de Gestão de Negócios, 16(52), 448-465.

Economic Planning Unit, P. M. D. (2015). Eleventh Malaysia Plan, 2016-2020: Anchoring growth on people. Retrieved from http://planipolis.iiep.unesco.org/en/2015/ eleventh-malaysia-plan-2016-2020-anchoring-growthpeople-6285

Evald, M., R., M., \& Senderovitz, M. (2013). Exploring internal corporate venturing in SMEs: Effectuation at work in a new context. Journal of Enterprising Culture, 21(3), 275-299.

Fallah, M. H., \& Lechler, T. G. (2008). Global innovation performance: Strategic challenges for multinational corporations. Journal of Engineering and Technology Management, 25(1-2), 58-74.

Frederiksen, D. L., \& Brem, A. (2017). How do entrepreneurs think they create value? A scientific reflection of Eric Ries' Lean Startup approach. International Entrepreneurship and Management Journal, 13(1), 169-189.

Friedman, Y., \& Carmeli, A. (2017). The influence of decision comprehensiveness on innovative behaviours in small entrepreneurial firms: The power of connectivity. Innovation, 20(1), 61-83.

Fritzsche, D., \& Oz, E. (2007). Personal values' influence on the ethical dimension of decision making. Journal of Business Ethics, 75(4), 335-343.

Galvez, D., Enjolras, M., Camargo, M., Boly, V., \& Claire, J. (2018). Firm readiness level for innovation projects: A new decision making tool for innovation managers. Administrative Sciences, 8(1), 6. doi: 10.3390/ admsci8010006

García-Sánchez, E., García-Morales, V. J., \& MartínRojas, R. (2018). Influence of technological assets on organisational performance through absorptive capacity, organisational innovation and internal labour flexibility. Sustainability, 10(3), 770. doi: 10.3390/su10030770

GE Global Innovation Barometer (2014). Insight on disruption, collaboration and the future of work. Retrieve from http://www.gereports.com/innovation-barometer-2014/ 
George, J. M., \& Zhou, J. (2001). When openness to experience and conscientiousness are related to creative behaviour: An interactional approach. Journal of Applied Psychology, 86(3), 513-524.

Gerli, F., Gubitta, P., \& Tognazzo, A. (2011). Entrepreneurial Competencies and Firm Performance: an empirical study. In International Workshop on Human Resource Management, Seville, Spain, 8. Retrieved from https://www.researchgate. net/profile/Paolo_Gubitta/publication/228314296_ Entrepreneurial_Competencies_and_Firm_Performance_ An_Empirical_Study/links/00463526e019fdfeb9000000/ Entrepreneurial-Competencies-and-Firm-PerformanceAn-Empirical-Study.pdf

Gorgievski, M. J., Ascalon, M. E., \& Stephan, U. (2011). Small business owners' success criteria, a values approach to personal differences. Journal of Small Business Management, 49(2), 207-232.

Hair, J. F. Jr., Hult, G. T. M., Ringle, C., \& Sarstedt, M. (2017). A primer on partial least squares structural equation modeling (PLS-SEM). Thousand Oaks, Ca: Sage Publications.

Harms, R., \& Schiele, H. (2012). Antecedents and consequences of effectuation and causation in the international new venture creation process. Journal of international entrepreneurship, 10(2), 95-116.

Henseler, J., Ringle, C. M., \& Sarstedt, M. (2015). A new criterion for assessing discriminant validity in variancebased structural equation modeling. Journal of the academy of marketing science, 43(1), 115-135.

Hepper, E. G., Gramzow, R. H., \& Sedikides, C. (2010). Individual differences in self囚enhancement and self囚 protection strategies: An integrative analysis. Journal of personality, 78(2), 781-814.

Hirschi, A., \& Fischer, S. (2013). Work values as predictors of entrepreneurial career intentions: A longitudinal analysis of gender effects. Career Development International, 18(3), 216-231.

Hitt, M. A., Ireland, R. D., Camp, S. M., \& Sexton, D. L. (2002). Strategic entrepreneurship: Integrating entrepreneurial and strategic management perspectives. In M. A. Hitt, R. D. Ireland, S. M. Camp, \& D. L. Sexton
(Eds.). Strategic entrepreneurship: Creating a new mindset (Cap. 1, pp. 1-16). New Jersey: John Wiley \& Sons.

Holland, D. V., \& Shepherd, D. A. (2013). Deciding to persist: Adversity, values, and entrepreneurs' decision policies. Entrepreneurship Theory and Practice, 37(2), 331-358.

Hu, L. T., \& Bentler, P. M. (1999). Cutoff criteria for fit indexes in covariance structure analysis: Conventional criteria versus new alternatives. Structural Equation Modeling: A Multidisciplinary Journal, 6(1), 1-55.

Hutzschenreuter, T., \& Horstkotte, J. (2010). Knowledge transfer to partners: A firm level perspective. Journal of Knowledge Management, 14(3), 428-448.

Jalonen, H. (2012). The uncertainty of innovation: A systematic review of the literature. Journal of Management Research, 4(1), 1-47.

Jasimuddin, S. M., \& Hasan, I. (2015). Organizational culture, structure, technology infrastructure and knowledge sharing. Vine, 45(1), 67-88.

Jaussaud, J., \& Schaaper, J. (2006). Control mechanisms of their subsidiaries by multinational firms: A multidimensional perspective. Journal of International Management, 12(1), 23-45.

Jaworski, B. J., \& Kohli, A. K. (1993). Market orientation: Antecedents and consequences. The Journal of Marketing, 57(3), 53-70.

Jones, J. L. S., \& Linderman, K. (2014). Process management, innovation and efficiency performance. Business Process Management Journal, 20(2), 335-358.

Jong, J., de, \& Hartog, D., den, (2010). Measuring innovative work behaviour. Creativity and Innovation Management, 19(1), 23-36.

Kanter, R. (1985). Supporting innovation and venture development in established companies. Journal of business venturing, 1(1), 47-60.

Kasof, J., Chen, C., Himsel, A., \& Greenberger, E. (2007). Values and creativity. Creativity Research Journal, 19(2-3), 105-122. 
Kellermanns, F. W., Eddleston, K. A., Sarathy, R., \& Murphy, F. (2012). Innovativeness in family firms: A family influence perspective. Small Business Economics, 38(1), 85-101.

Kline, R. B. (2011). Principles and practice of structural equation modeling (3rd ed.). New York: Guilford Press.

Knight, F. (1921). Risk, uncertainty and profit. Boston, NY: Houghton Mifflin Company.

Kogut, B., \& Zander, U. (1992). Knowledge of the firm, combinative capabilities, and the replication of technology. Organisation Science, 3(3), 383-397.

Kraus, S., Harms, R., \& Schwarz, E. J. (2006). Strategic planning in smaller enterprises-new empirical findings. Management Research News, 29(6), 334-344.

Küpper, D., \& Burkhart, T. (2009). Effectuation in the context of R\&D projects: Characteristics and impact on project performance. Academy of Management Proceedings, 2009(1), 1-6.

Larson, K. L., White, D. D., Gober, P., \& Wutich, A. (2015). Decision making under uncertainty for water sustainability and urban climate change adaptation. Sustainability, 7(11), 14761-14784.

Léger-Jarniou, C., \& Tegtmeier, S. (2017). Introduction: reopening the debate-a Delphi panel of the leading scholars in research on entrepreneurial opportunities. In C. Léger-Jarniou, \& S. Tegtmeier (eds). Research handbook on entrepreneurial opportunities (pp. 1-42). UK: Edward Elgar Publishing.

Lepistö, T., Mäkitalo-Keinonen, T., \& Valjakka, T. (2019). Opportunity recognition in a hub-governed networkinsights from garage services. International Entrepreneurship and Management Journal, 15(1), 257-280.

Leskinen, R. (2011). Success in the female entrepreneurial networking process. Annals of Innovation \& Entrepreneurship, 2(1), 1-25.

Lo, M. C., Wang, Y. C., Wah, C. R. J., \& Ramayah, T. (2016). The critical success factors for organisational performance of SMEs in Malaysia: A Partial Least Squares approach. Revista Brasileira de Gestão de Negócios, 18(61), 370-391.
Malaysia Science and Technology Information Centre (2019). Global Innovation Index (GII). Retrieved from https://mastic.mestecc.gov.my/statistic/internationalranking/global-innovation-index

Malaysian Industrial Development Authority (2006). Malaysia performance of the manufacturing and services sectors. Retrieved from www.mida.gov.my

Matalamäki, M. J. (2017). Effectuation, an emerging theory of entrepreneurship-towards a mature stage of the development. Journal of Small Business and Enterprise Development, 24(4), 928-949.

McKelvie, A., DeTienne, D. R., \& Chandler, G. N. (2013). What is the appropriate dependent variable in effectuation research?. Frontiers of Entrepreneurship Research, 33(4), 4.

Michailova, S., \& Nielsen, B. B. (2006). MNCs and knowledge management: A typology and key features. Journal of Knowledge Management, 10(1), 44-54.

Moilanen, S. (2007). Knowledge translation in management accounting and control: A case study of a multinational firm in transitional economies. European Accounting Review, 16(4), 757-789.

Mollick, E. (2012). People and process, suits and innovators: The role of individuals in firm performance. Strategic Management Journal, 33(9), 1001-1015.

Mustapha, M. (2014). Monitoring costs of multinational companies: An agency theory perspective. Asian Journal of Business and Accounting, 7(2), 23-43.

Nelson, R. R., \& Winter, S. G. (1982). An evolutionary theory of economic change. Cambridge, MA: The Belknap Press.

Noordin, R., Zainuddin, Y., Mail, R., \& Sariman, N. K. (2015). Performance outcomes of strategic management accounting information usage in Malaysia: Insights from electrical and electronics companies. Procedia Economics and Finance, 31, 13-25.

Oliveira, D. D. L., Maçada, A. C. G., \& Oliveira, G. D. (2016). Business value of IT capabilities: effects on processes and firm performance in a developing country. Revista Brasileira de Gestão de Negócios, 18(60), 245-266. 
Pang, J. S. (2010). The achievement motive: A review of theory and assessment of achievement, hope of success, and fear of failure. Implicit motives, 1, 30-71.

Park, C. H., Song, J. H., Lim, D. H., \& Kim, J. W. (2014). The influences of openness to change, knowledge sharing intention and knowledge creation practice on employees' creativity in the Korean public sector context. Human Resource Development International, 17(2), 203-221.

Phipps, S. T., \& Prieto, L. C. (2012). Knowledge is power? An inquiry into knowledge management, its effects on individual creativity, and the moderating role of an entrepreneurial mindset. Academy of Strategic Management Journal, 11(1), 43-58.

Preacher, K. J., \& Hayes, A. F. (2008). Asymptotic and resampling strategies for assessing and comparing indirect effects in multiple mediator models. Behaviour research methods, 40(3), 879-891.

Purc, E., \& Laguna, M. (2019). Personal Values and Innovative Behaviour of Employees. Frontiers in Psychology, 10,865 .

Radam, A., Abu, M. L., \& Abdullah, A. M. (2008). Technical efficiency of small and medium enterprise in Malaysia: A stochastic frontier production model. International Journal of economics and Management, 2(2), 395-408.

Ramamoorthy, N., Flood, P. C., Slattery, T., \& Sardessai, R. (2005). Determinants of innovative work behaviour: Development and test of an integrated model. Creativity and innovation management, 14(2), 142-150.

Ramstetter, E. D., \& Ahmad, S. B. H. (2009, march). Foreign Multinationals in Malaysian Manufacturing After the Crisis [Working Paper Series Vol. 2009-13]. Retrieved from http://www.agi.or.jp/user03/836_188_20110622134613.pdf

Ratnaningsih, I. Z., Prasetyo, A. R., \& Prihatsanti, U. (2016). Predicting innovative behaviour among employees in a manufacturing company: the role of psychological capital. ANIMA Indonesian Psychological Journal, 31(2), 84-90.

Roach, D. C., Ryman, J. A., \& Makani, J. (2016). Effectuation, innovation and performance in SMEs:
An empirical study. European Journal of Innovation Management, 19(2), 214-238.

Roberts, P. W., \& Amit, R. (2003). The dynamics of innovative activity and competitive advantage: The case of Australian retail banking, 1981 to 1995. Organisation Science, 14(2), 107-122.

Rosli, M. M., \& Sidek, S. (2013). The impact of innovation on the performance of small and medium manufacturing enterprises: Evidence from Malaysia. Journal of Innovation Management in Small \& Medium Enterprises, 2013, 1-16.

Sagiv, L., \& Schwartz, S. H. (2007). Cultural values in organisations: Insights for Europe. European Journal of International Management, 1(3), 176-190.

Sapienza, H. J., Smith, K. G., \& Gannon, M. J. (1988). Using subjective evaluations of organizational performance in small business research. American Journal of Small Business, 12(3), 45-53.

Sarasvathy, S. D. (2001). Causation and effectuation: Toward a theoretical shift from economic inevitability to entrepreneurial contingency. Academy of management Review, 26(2), 243-263.

Sarasvathy, S. D. (2008). Elements of Entrepreneurial Expertise. Northampton: Edward Elgar.

Sarstedt, M., Hair, J. F., Jr., Cheah, J. H., Becker, J. M., \& Ringle, C. M. (2019). How to specify, estimate, and validate higher-order constructs in PLS-SEM. Australasian Marketing Journal (AMJ), 27(3), 197-211.

Sarstedt, M., Wilczynski, P., \& Melewar, T. C. (2013). Measuring reputation in global markets-A comparison of reputation measures' convergent and criterion validities. Journal of World Business, 48(3), 329-339.

Schwartz, S. H. (1992). Universals in the content and structure of values: Theoretical advances and empirical tests in 20 countries. Advances in experimental social psychology, 25(1), 1-65.

Schwartz, S. H. (2003). A proposal for measuring value orientations across nations. Questionnaire Package of the European Social Survey, 259(290), 261. 
Schwartz, S. H. (2007). Universalism values and the inclusiveness of our moral universe. Journal of cross-cultural psychology, 38(6), 711-728.

Schwartz, S. H., \& Bardi, A. (2001). Value hierarchies across cultures taking a similarities perspective. Journal of Cross-Cultural Psychology, 32(3), 268-290.

Schwartz, S. H., Cieciuch, J., Vecchione, M., Davidov, E., Fischer, R., Beierlein, C., ... \& Dirilen-Gumus, O. (2012). Refining the theory of basic individual values. Journal of Personality and Social Psychology, 103(4), 663- 688.

Shalley, C. E., \& Gilson, L. L. (2004). What leaders need to know: A review of social and contextual factors that can foster or hinder creativity. The Leadership Quarterly, 15(1), 33-53.

Singh, R. K., Garg, S. K., \& Deshmukh, S. G. (2008). Strategy development by SMEs for competitiveness: A review, benchmarking; An International Journal, 15(5), 525-547.

Sniazhko, S. (2019). Uncertainty in decision-making: A review of the international business literature. Cogent Business \& Management, 6(1), 1-32.

Sousa, C. M., \& Coelho, F. (2011). From personal values to creativity: evidence from frontline service employees. European Journal of Marketing, 45(7/8), 1029-1050.

Sun, X., \& Bisht, R. K. (2013). Causation and effectuation in the context of product development process in a largesized established company. (Master's thesis). Department of Business Administration, School of Economics and Management, Lund University. Lund, Sweden. Retrieved from http://lup.lub.lu.se/luur/download?func=download File\&recordOId=3912698\&fileOId $=3912700$

Svensrud, E., \& Åsvoll, H. (2012). Innovation in large corporations: A development of the rudimentary theory of effectuation. Academy of Strategic Management Journal, 11(1), 59-90.

Thamhain, H. J. (2003). Managing innovative R\&D teams. R\&D Management, 33(3), 297-311.

Tyszka, T., Cieślik, J., Domurat, A., \& Macko, A. (2011). Motivation, self-efficacy, and risk attitudes among entrepreneurs during transition to a market economy. The Journal of Socio-Economics, 40(2), 124-131.

Wang, C. L., Hult, G. T. M., Ketchen Jr, D. J., \& Ahmed, P. K. (2009). Knowledge management orientation, market orientation, and firm performance: An integration and empirical examination. Journal of Strategic Marketing, 17(2), 99-122.

Werhahn, D., Mauer, R., Flatten, T., \& Brettel, M. (2015). Validating effectual orientation as strategic direction in the corporate context. European Management Journal, 33(5), 305-313.

Whitaker, J., Ekman, P., \& Thompson, S. (2017). How multinational corporations use information technology to manage global operations. Journal of Computer Information Systems, 57(2), 112-122.

Wilson, F. A., \& Goldman-Rakic, P. S. (1994). Viewing preferences of rhesus monkeys related to memory for complex pictures, colours and faces. Behavioural Brain Research, 60(1), $79-89$.

Yildiz, H. E., Murtic, A., Zander, U., \& Richtnér, A. (2019). What fosters individual-level absorptive capacity in MNCs? An extended motivation-ability-opportunity framework. Management International Review, 59(1), 93-129.

York, J. G., \& Venkataraman, S. (2010). The entrepreneurenvironment nexus: Uncertainty, innovation, and allocation. Journal of Business Venturing, 25(5), 449-463.

Yunis, M., Jamali, D., \& Hashim, H. (2018). Corporate social responsibility of foreign multinationals in a developing country context: insights from Pakistan. Sustainability, 10(10), 3511. doi: https://doi.org/10.3390/ su 10103511

Zakaria, N., Abdullah, N. A. C., \& Yusoff, R. Z. (2016). The innovation-performance linkage: Empirical evidence of Malaysian manufacturing SMEs. In International Soft Science Conference (pp. 419-424).

Zarzycka, E., Dobroszek, J., Lepistö, L., \& Moilanen, S. (2019). Coexistence of innovation and standardization: Evidence from the lean environment of business process 
outsourcing. Journal of Management Control, 30(3), 251-286.

Zeschky, M., Daiber, M., Widenmayer, B., \& Gassmann, O. (2014). Coordination in global R\&D organisations: An examination of the role of subsidiary mandate and modular product architectures in dispersed $\mathrm{R} \& \mathrm{D}$ organisations. Technovation, 34(10), 594-604.

Zhao, X., Lynch, J. G., Jr., \& Chen, Q. (2010). Reconsidering Baron and Kenny: Myths and truths about mediation analysis. Journal of consumer research, 37(2), 197-206. 
Appendix - Measurement Items

Individual Values (Schwartz, 2003; 1 = Very untrue of me to 7 = Very true of me)

Openness to change:

- It is important to me to think of new ideas and be creative. I like to do things in my own original way.

- It is important to me to make my own decisions about what I do. I like to be free and not depend on others.

- I like surprises and am always looking for new things to do. I think it is important to do many different things in life.

- I look for adventures and like to take risks. I want to have an exciting life.

- It is important to me to have a good time. I like to "spoil" myself.

- I seek every chance I can to have fun. It is important to me to do things that give me pleasure.

Self-transcendence:

- It is very important to me to help the people around me. I want to care for other people.

- It is important to me to be loyal to my friends. I want to devote myself to the people who are close to me.

- I think it is important for everyone in the world to be treated equally. I want justice for everybody, even for people I do not know.

- It is important to me to listen to people who are different from me. Even when I disagree with them, I still want to understand them.

- I strongly believe that people should care for nature. Looking after the environment is important to me.

Effectuation (Chandler et al., 2011; 1 = Strongly disagree to $7=$ Strongly agree)

Experimentation:

- I experiment with different products and/or business models.

- The product/service that I provide now is essentially the same as the one that was originally conceptualized.

- The product/service that I provide now is substantially different from the one I first imagined.

- I try a number of different approaches until I find a business model that works.

Affordable Loss:

- I am careful not to commit more resources than I can afford to lose.
- I am careful not to risk more money than I am willing to lose with the initial idea.

- I am careful not to risk so much money that the company would be in real financial trouble if things do not work out.

Flexibility:

- I allow the business to evolve as opportunities emerge.

- I adapt what I am doing to the resources I have.

- I am flexible and take advantage of opportunities as they arise.

- I avoid courses of action that restrict my flexibility and adaptability.

Pre-commitment:

- I use a substantial number of agreements with customers, suppliers and other organisations and people to reduce the amount of uncertainty.

- I use pre-commitments from customers and suppliers as often as possible.

Innovative Behaviour (de Jong and den Hartog, 2010; 1 = Strong disagree to 7 = Strongly agree)

- I pay attention to issues that are not part of my daily work.

- I usually wonder how things can be improvised.

- I search out new working methods, techniques or instruments.

- I create original solutions for problems.

- I find new approaches to executing tasks.

- I make important organisational members enthusiastic about innovative ideas.

- I try to convince people to support an innovative idea.

- I systematically introduce innovative ideas into work practices.

- I contribute to the implementation of new ideas.

- I put an effort into developing new things.

Firm Performance (Jaworski and Kobli, 1993; 1 = Strong disagree to 7 = Strongly agree)

- The overall performance of our firm met expectations last year.

- The overall performance of our firm exceeded that of our major competitors last year. 


\section{Financial support:}

This research was sponsored by Universiti Putra Malaysia under UPM Grant Putra Siswazah, Project Number: 9536100.

\section{Conflicts of interest:}

The authors have no conflict of interest to declare.

\section{Copyrights:}

RBGN owns the copyrights of this published content.

\section{Plagiarism analysis:}

RBGN performs plagiarism analysis on all its articles at the time of submission and after approval of the manuscript using the iThenticate tool.

\section{Authors:}

1. Thanuja Rathakrishnan, PhD in Business Economics, Universiti Putra Malaysia, Serdang, Malaysia.

E-mail: thanuja87@outlook.com

2. Siew Imm Ng, PhD in Management, University of Western Australia, Perth.

E-mail: imm_ns@upm.edu.my

3. Jo Ann Ho, PhD in Business Ethics, Cardiff Business School, Cardiff University, United Kingdom. Email: ann_hj@upm.edu.my

4. Dahlia Zawawi, PhD in Organizational Behaviour, University of Reading, Berkshire, United Kingdom.

E-mail: dahlia@upm.edu.my

\section{Authors' Contributions:}

Thanuja Rathakrishnan: Definition of research problem; Development of hypotheses or research questions (empirical studies); Development of theoretical propositions (theoretical work); Definition of methodological procedures; Data Collection; Literature review; Statistical analysis; Analysis and interpretation of data; Critical revision of the manuscript; Manuscript writing.

Siew Imm Ng: Definition of research problem; Development of hypotheses or research questions (empirical studies); Development of theoretical propositions (theoretical work); Definition of methodological procedures; Literature review; Statistical analysis; Analysis and interpretation of data; Critical revision of the manuscript.

Jo Ann Ho: Definition of research problem; Development of hypotheses or research questions (empirical studies); Development of theoretical propositions (theoretical work); Definition of methodological procedures; Statistical analysis; Analysis and interpretation of data.

Dahlia Zawawi: Definition of research problem; Development of hypotheses or research questions (empirical studies); Development of theoretical propositions (theoretical work); Definition of methodological procedures; Statistical analysis; Proofreading. 